\title{
As especificidades de análise do espaço, lugar, paisagem e território na geográfica
}

Resumo: Cada vez mais concepções de espaço, paisagem, lugar e território têm sido usados na análise espacial da sociedade. No entanto, isso não quer dizer que se está tendo uma boa compreensão dessas categorias. A nosso ver o que estamos presenciando, principalmente nós geógrafos que, muita das vezes, advogamos que essas categorias de análise fazem parte de nossa alçada exclusivamente, o que não se faz verdade, muito embora faça parte de nossas atribuições expressar o que são e o que não são essas categorias. Entendemos que o cerne da Geografia é dá respostas para uma análise mais pormenorizada da espacialidade social, sendo que isso depende cada vez mais do conhecimento ao que respeita o significado das categorias espaciais. Assim, propomos, neste artigo, refletir sobre as noções de espaço, lugar, paisagem e território, a fim de contribuir de modo analítico para uma boa compreensão dessas categorias, para um construto de interpretação sócio-espacial.

\section{The specific analysis of space, place, landscape and territory in geography}

\begin{abstract}
Increasingly concepts of space, landscape, place and territory have been used in spatial analysis of society. However, this does not mean that you're having a good understanding of these categories. We believe what we are witnessing, we mainly geographers, much of the time, we advocate that these categories of analysis are part of our responsibility only, which is not true, even though part of our remit to express what is and what these categories are not. We understand that the crux of geography is the answer to a more detailed analysis of social spatiality, and that increasingly depends on knowledge about the meaning of spatial categories. Therefore, we propose in this article reflects on the notions of space, place, landscape and territory in order to contribute to a good analytical understanding of these categories to construct a socio-spatial interpretation.
\end{abstract}

* Mestre em Desenvolvimento e Meio Ambiente UFC, mestrando em Filosofia pela UFC (2010-2012)

\section{Palavras-chave:}

Espaço; lugar; paisagem; território; ciência geográfica.

Key-words: Space, place, landscape, territory, geographic science. 


\section{Introdução}

Analisar como tem se dado a utilização dos conceitos e categorias geográficas de análise espacial, bem como os mesmos tem se manifestado é algo que em uma primeira vista parece um pouco trabalhoso, haja vista a enormidade de usos que essas categorias têm tido, e em sua grande maioria sem nenhuma preocupação com seus melhores significados. Em vários casos têm se mostrado algo bastante irresponsável, pois não se tem dado a devida atenção do uso dos termos. Uns utilizam os conceitos e categorias de forma superficiais, outros misturam os sentidos como se os conceitos e as categorias em alguns casos fossem as mesmas coisas ou bem símiles. 0 certo é que, como por exemplo, que: espaço é espaço e não território. Isso vale, também, para os outros conceitos da ciência geográfica, tais como, lugar, paisagem e território.

Neste trabalho, queremos mostrar que cada conceito tem seu lugar específico e que fazer essa distinção evoca um respeito de pesquisador com os longos anos de estudos e pesquisas e abstrações que a história do pensamento geográfico teve e tem ao delimitar o escopo de cada categoria geográfica. Assim, faz-se necessário considerarmos a importância da re-análise do espaço, do lugar, da paisagem e do território, com a intenção colocar mais "lenha na fogueira" desse grande debate que vem varando séculos entre as correntes internas da Geografia, bem como de outros campos científicos que usufrui e utilizam as categorias espaciais supramencionadas. Desse modo, estamos colocando cada coisa em seu lugar, isto é, que cada categoria tem seu uso específico e deve ser aplicada para dá conta de interpretar diferentes recortes da realidade sócio-espacial.

Vale ressaltar que a intenção de colocar cada conceito em seu devido lugar, não quer dizer que "bateremos o martelo" e diremos que essa ou aquela definição é a correta e que deve ser sempre essa ou aquela que deverá ser utilizada. Isso não quer dizer, também, que nossa intenção seja encontrar uma definição finalista para os conceitos e categorias, mas que em algumas ocasiões deveremos prezar por esse ou por aquele conceito e em outros casos ocorrerão imbricações entre esse e aquele conceito e/ou categorias. Até porque trabalhar com conceito é bem mais complexo que cravar um sentido único para o mesmo, visto que dependendo da posição epistemológica com que se trate o conceito, o mesmo terá esse ou aquele maior destaque.

O que vale deixar claro é que se faz necessário que se tenha, pelo menos, uma noção mínima do que seja cada um dos conceitos/categorias, sem que, de forma descabida, um seja utilizado, quando na realidade a noção, ou a melhor opção seja a de outro conceito ou de outra categoria.

Para desenvolvermos o presente texto, observaremos o que Gomes escreve: "[...] podemos conceber que os objetos de investigação são construídos pelo tipo de questões a eles endereçadas, sendo estas questões que os conformam, os limitam, os criam, e não o inverso, como, por vezes, tendemos a imaginar". (GOMES, 2002, p.292).

Milton Santos assevera a assertiva acima e diz que: "os mesmos objetos podem dialogar com as mais diversas disciplinas [...] A questão que se coloca é, pois, sobretudo, uma questão de método, isto é, da construção de um sistema intelectual que permita, analiticamente, abordar uma realidade, a partir de um ponto de vista". (SANTOS, 1999, p. 62).

A partir das proposições acima compreendemos que o objeto, o fenômeno da investigação/ análise não é algo dado a priori, todavia é um construto. Nesse sentido, não queremos aqui dizer que tenhamos que buscar um objeto geográfico em si, que as categorias espaciais sejam exclusividade

Geografia Ensino \& Pesquisa, v. 16, n.2 p. 23 - 30, maio/ago. 2012

As especificidades de análise do espaço, lugar, paisagem e território na geográfica da Geografia, muito embora entendamos que os geógrafos são peças importantes para o debate entre outros cientistas que se utilizam de categorias espaciais no desvendar processual da realidade.

Atualmente vislumbramos com mais clareza a existência de duas perspectivas de abordagem espacial. A primeira é a que se debruça na descrição das formas físicas (morfologias) e/ou ambientais de uma determinada região, área percebidas como elucidativa, às vezes determinantes, da realidade social. A segunda tem a intenção de mostrar o espaço como algo frenético, ativo, no processo de organização social. Isto é, o espaço é produto e produtor. É ao mesmo tempo paciente 
e agente nessa ativa dinâmica. Nesse caso, é que surge a defesa de que cabe a Geografia a análise mais acurada; a promoção de uma interpretação dos processos, dos fenômenos por meio de um vislumbre de análise espacial novo, isto é, renovado.

Essa análise espacial passa necessariamente por um entendimento mais pormenorizado das categorias espaciais de análise, no que diz respeito a seus significados, bem como das possibilidades de usos e de análises de cada uma das categorias. Nesse sentido, o presente artigo se debruça fundamentalmente em uma análise comparativa dos principais conceitos e entre as correntes geográficas que debatem os conceitos acima aventados, mostrando que dependendo na postura metodológica, seja positivista, fenomenológica ou crítica dialética, podemos emitir respostas salutares para as problemáticas que estejamos dispostos a compreender.

Assim, baseado em uma revisão bibliográfica, pesquisa indireta, em maior escala, sobre conceitos "chaves" da Geografia e de como esses conceitos têm sido encarados e anunciados, é que fizemos e propomos a presente análise.

\section{O espaço como categoria de análise}

Nossa primeira análise será endereçada ao conceito de espaço como categoria de análise da realidade sócio-espacial em um viés eminentemente geográfico. Isso como desafio de construir instrumentos analíticos comprometidos com a interpretação dos fundamentos da realidade sócioespacial contemporânea.

Nesse sentido, vejamos alguns teóricos sobre a questão. Para Gomes (2002, p. 172), três características definem o "espaço geográfico": 1) o espaço é sempre uma extensão fisicamente constituída, concreta, material, substantiva; 2) o espaço compõe-se pela dialética entre a disposição das coisas e as ações ou práticas sociais; 3 ) a disposição das coisas materiais tem uma lógica ou coerência.

Para esse autor (Ibid., p.290), "[...] a análise espacial deve ser concebida como um diálogo permanente entre a morfologia e as práticas sociais ou comportamentos". Para Milton Santos (1999, p. 18), essa questão, de aporte analítico, pressupõe que "[...] o espaço seja definido como um conjunto indissociável de sistemas de objetos e de sistemas de ações".

Gomes afirma que, "[...] as formas são portadoras de significados e sentidos" (1997, p.38). Santos, por sua vez, define o espaço como um composto de "formas conteúdo", ou seja, formas que só existem em relação aos usos e significados, essa relação forma-conteúdo é a cauda de sua existência.

Como o espaço não é algo dado como nos propõe Soja em seu "espaço em si" (1993), mesmo quando o mesmo tende remediar e diz que sua organização e sentido são produtos da transformação e experiência sociais. 0 espaço é, na realidade, um construto social dialético. Mesmo sabendo disso, se desvincular de uma visão física do espaço, de algo dado, de um "espaço em si" é algo bem trabalhoso.

Assim, salientamos que o espaço é um equilíbrio, uma espécie de equação engendrada pela forma e pelos diferentes sentidos que ela é capaz de suscitar e condicionar. Equacionados e construídos socialmente, os sentidos e significações da organização do espaço são sempre advindos de uma perene relação, isto é, o espaço é uma constituição relacional, relação entre objetos/coisas espacialmente distribuídas, da relação entre os objetos e suas funções, o que traz os seus sentidos e significados, da relação entre esses objetos e as vivências, isto é, das práticas sociais.

Essa produção espacial de significados ocorre todos os dias, nas nossas idas e vindas, no trabalho, na sociabilidade, nas relações de várias ordens, isto é, nossa relação cotidiana com o espaço se dá através da construção de significados, ou seja, nós promovemos uma (re)significação.

Geografia Ensino \& Pesquisa, v. 16, n.2 p. 23 - 30, maio/ago. 2012

Lopes, J. G.

ISSN 2236-4994 
Podemos asseverar que a "dimensão relacional" da organização espacial referenciada por Gomes (2002), tem similitudes na "condição de inseparabilidade" entre sistemas de objetos e sistemas de ações, defendida por Santos. Pois Santos também mostra que não se trata de sistemas tomados um a um, pois objetos/coisas e ações (conteúdos) interagem continuamente, formando um conjunto indissociável, solidário e ao mesmo tempo contraditório. Nesse escopo, Santos (1999, p. 77) "A ação não se dá sem que haja um objeto; e, quando exercida, acaba por se redefinir como ação e por redefinir o objeto".

Gomes (2002, p. 36), por sua vez, admite que a organização concreta das coisas, isto é, seu arranjo físico possibilita que certas ações se (re)produzam, ou seja, as práticas sociais são dependentes de determinada distribuição ou ordenação das coisas. É desse modo que o espaço encontra sua frenética dinâmica e se transforma, isto é, mostra seu caráter de constante mutabilidade.

Sob essas perspectivas de conceber o espaço, salientamos que as relações que promovem a dinâmica dialética formativa e contraditória do espaço se dão no transcurso do tempo, cabe lembrar, que as formas ou objetos e as ações ou comportamentos mudam e propõem diferentes organizações desse espaço. Para Santos (1999, p.62-63), isso impõe a necessidade de captar em cada momento histórico o que é mais característico do sistema de objetos e de práticas vigentes. Por esse viés, é possível perceber que o processo sócio-espacial, que reúnem objetos e ações, está fundado, ao mesmo tempo, na perspectiva do tempo passado com suas realidades sociais e materiais e na perspectiva do tempo presente em todo o seu processo de construção.

Contudo, se concebermos o espaço como resultado da relação entre formas e comportamentos ou conseqüência da inseparabilidade entre sistemas de objetos e de ações, torna-se óbvio que uma geografia interessada apenas num determinado tipo de objetos ou numa dada classe de ações "[...] não seria capaz de dar conta da realidade que é total e jamais é homogênea" (SANTOS, 1999, p. 78).

Santos (Ibid., p. 88) assevera que "o espaço é a síntese, sempre provisória, entre o conteúdo social e as formas espaciais". Dessa forma, o espaço é um misto entre o social e o físico.

\section{O lugar como categoria de análise}

É consenso que as concepções da categoria lugar para a ciência geográfica estão atreladas com as discussões travadas pela Geografia humana, sendo que essa categoria tem dois lastros de acepção principais: a geografia fenomênica/humanista (geografia cultural) e a geografia crítica (marxista - materialismo/histórico/dialético).

Na perspectiva humanista, preocupada fundamentalmente com a relação homem-natureza/ ambiente sob o prisma da subjetividade, o interesse é fundamentar o lugar enquanto base da existência humana, mas existência enquanto experiência pessoal, mediatizada por símbolos e significas próprios, subjetivos. Para Tuan (1983), espaço e lugar são expressões interligadas. Para eles os espaços estão dados e na medida em que conhecemos e atribuímos alguma importância, algum valor para o mesmo, o lugar se engendra. É como se os lugares formassem a teia, as articulações do espaço. O lugar para essa corrente geográfica de pensamento advém do espaço na medida em que agimos intencionalmente, quando focalizamos o espaço em torno das experiências, sejam casuais, simples, banais ou aquelas que causam impactos, isto é, as que chamamos de experiências fenomenais.

Ainda para os humanistas a essência do lugar mediatizado pelo espaço através das experiências é a essência, é o centro onde são experimentados os eventos mais expressivos de nossa seleta vida, ou seja, o viver e o habitar, o uso e o consumo, o trabalho, o entretenimento, 0 lazer, o prazer e etc. Para isso se fazer, o fundamento onde se desenrola tudo isso é o lugar, que assume, além da ação e da percepção em sua experiência concreta ou simbólica, outros estamentos: o lar (casa, ou qualquer local considerado como lar), o vilarejo ou bairro, a cidade, o país e o mundo. 
Ao considerar essa concepção Holzer (1999), acredita que tanto para o indivíduo como para o grupo, o aumento da abrangência impossibilita, progressivamente, um relacionamento espacial direto, remetendo-nos a uma visão cada vez mais esfacelada dos lugares.

Na perspectiva geográfica radical-crítica, o lugar tem qualidade de construção social que se dá ao longo da história, isto é, uma construção sócio-histórica, que cumpre determinadas atribuições na lógica social. Por meio de suas formas materiais e imateriais, o lugar é um meio de promoção da funcionalidade do mundo.

Assim, não importa qual época estamos analisando na história, o mundo, a sociedade se define como um conjunto de possibilidades, e cada lugar têm sua diferença por realizar apenas uma perspectiva das muitas possibilidades que existe.

Santos (1999) entende que a ordem mundial/global tenta impor, por vários canais uma racionalidade homogeneizante, porém os lugares seguindo sua própria racionalidade contraargumenta e enfrenta essa racionalidade única. Assim, a relação local-global está manifesta da seguinte maneira: enquanto o global expõe as escalas superiores e externas, o local funda a escala do cotidiano, que está pautado na comunicação, a vizinhança, a emoção, a intimidade, a cooperação. Nesse sentido, Santos (Ibid., p. 273) assevera que, "cada lugar é, ao mesmo tempo, objeto de uma razão global e de uma razão local, convivendo dialeticamente".

Para além das frentes de interpretação acima, existe uma que tenta fazer uma ligação entre as duas correntes (humanista e crítica) ao enquadrar o lugar como um campo de articulação das questões cruciais para a compreensão da existência humana e sua relação com um ambiente cada vez mais fragmentado e globalizado. (FERREIRA, 2000). Oakes (Apud, FERREIRA, 2000), um dos autores que atesta essa perspectiva. Para ele, o lugar é o sítio de identidades significativas e atividade imediata, é uma conseqüência de ligações que o convertem mais numa teia/rede dinâmica do que uma localização específica. Ainda para ele, o lugar não deve ser compreendido como um contraponto conceitual a uma vaga modernidade "deslugarizada", pois o que acontece no lugar não é meramente um embate frente às tentativas de hegemonia histórica e espacial, mas uma luta para nos colocarmos como sujeitos espaciais e históricos.

\section{A paisagem como categoria de análise}

A categoria paisagem para Geografia, em linhas gerais, esteve muito ligada, e ainda está, aquilo que cognominamos espectro visível, isto é, a ideia de formas visíveis. Mas é a partir do final da década de 1960 e início da década de 1970 que as análises geográficas passaram a figurar de modo mais freqüente nos estudos em Geografia sobre essa categoria em duas linhas de frente, na perspectiva sistêmica e na cultural.

Na perspectiva sistêmica, a paisagem é compreendida como uma realidade posta, ou seja, realidade objetiva. Nesse caso, a paisagem é o produto de um imbricamento dinâmico, maleável entre os componentes formadores da paisagem, elementos físico-naturais e sociais. Essa dinâmica, para o viés sistêmico é única para cada porção do espaço, e torna a paisagem um conjunto singular, inseparável e em constante mutação.

Essa dinâmica relacional e complexa entre seus componentes é baseada na metodologia geossistêmica, que é hierarquicamente organizado, mas dinâmico e flexível. Nessa linha de pensamento, conforme seus estudiosos, ocorre uma contribuição salutar, pois a mesma revitaliza a perspectiva de integração e de totalidade da paisagem geográfica.

Pelo prisma cultural, a paisagem está referenciada para o sentido de percepção espacial. $\mathrm{Na}$ realidade a paisagem é um entremeio entre o mundo das coisas e o da subjetividade humana. Cosgrove (1998) pontua que "a paisagem [...] é uma maneira de ver, [...] de compor e harmonizar 0 mundo externo em uma cena, em uma unidade visual" (p.98,99).

Geografia Ensino \& Pesquisa, v. 16, n.2 p. 23 - 30, maio/ago. 2012

Lopes, J. G. 
Entretanto, se levarmos em consideração que a paisagem é uma porção do espaço captada pelo olhar, não podemos esquecer, todavia que a captação da paisagem não se faz passivamente, mas nós organizamos e tecemos, aos mesmos, sentidos, desse modo a paisagem apreendida é construída na medida em que damos à mesma significância.

Assim, a categoria paisagem tende a evidenciar a coexistência de objetos e formas em sua face sociocultural manifesta. Desse modo, se a paisagem, como um conjunto de formas naturais e culturais associadas em um determinado espaço Rozendhal (1998), traduz-se num "campo de visibilidade", ao ser oferecida a nossa percepção e a nossa subjetividade e experiência, convertese num "campo de significação" individual e coletiva. Nesse sentido, a paisagem apresenta perspectivas variadas.

\section{O território como categoria de análise}

O início de utilização do conceito território tem por fundamento as concepções de Friedrich Ratzel, final do século XIX. Para o mesmo, o território é uma área/parcela da superfície da terra usufruída por um grupo humano. Em relação a essa perspectiva, vale salientar, que o território aqui tem um caráter "etológico" e simplista, pois a ideia de território, nesse caso, se restringe às áreas que são objeto de atuação direta dos seres humanos e, assim, tende a confundir território e espaço, o que, também proporciona uma marginalização do caráter político inerente território.

O campo da Geografia política começa a valorizar a dimensão política do território, mas em referência ao território nacional, ou seja, na perspectiva do Estado-nação. A escola francesa, por sua vez, capitaneada, principalmente por Vidal de La Blache contrapõe essa ideia com 0 Possibilismo, final do século XIX e início do XX, trazendo o conceito de região em contraposição com o do território. Em resumo, a região entra em destaque frente aos outros conceitos geográficos (MORAES, 1997; GOMES, 2000).

O território só volta a entrar em cena nas discussões nos anos de 1970 como um conceito que atraia para si a responsabilidade de explicar a realidade. Gottmann (1973) afirma que o significado do território deve ter em sua explicação e compreensão, aportes relacionais.

Raffestin estabelece a diferença entre espaço e território: É essencial compreender bem que o espaço é anterior ao território. 0 território se forma a partir do espaço, é o resultado de uma ação conduzida por um ator sintagmático (ator que realiza um programa) em qualquer nível. Ao se apropriar de um espaço, concreta ou abstratamente [...] o ator "territorializa" o espaço. (RAFFESTIN, 1993, p. 143).

Assim, tornou-se necessário conceber o poder como sendo multidimensional, derivado de múltiplas fontes, inerente a todos os atores e presente em todos os níveis espaciais. Desse modo, é que o território passou a ser entendido como espaço mobilizado, como elemento decisivo às relações de poder (RAFFESTIN, 1993) e territorialidade como estratégia(s) utilizada(s) para delimitar e afirmar o controle sobre uma área geográfica, ou seja, para estabelecer, manter e reforçar esse poder (GOMES, 2002).

A ideia de poder, em relação ao território é, também, uma constante na compreensão analítica feita por Marcos Aurélio Saquet:

Geografia Ensino \& Pesquisa, v. 16, n.2 p. 23 - 30, maio/ago. 2012

As especificidades de análise do espaço, lugar, paisagem e território na geográfica o território é produzido espaço-temporalmente pelas relações de poder engendradas por um determinado grupo social. Dessa forma, pode ser temporário ou permanente e se efetiva em diferentes escalas, portanto, não apenas naquela convencionalmente conhecida como o "território nacional" sob gestão do Estado-Nação. (SAQUET, 2004, p. 81).

SOUZA, (1995) destaca dois importantes aspectos sobre o território: primeiramente, devese ter consciência que os territórios não têm uma dimensão espacial e temporal fixa, pois variam de tamanho (podendo inclusive ser "móveis" ou "flexíveis") e da mesma maneira que existem num 
dado momento, noutro poderão desaparecer; e, em segundo lugar, vários territórios podem ser apropriados simultaneamente pelo mesmo agente no mesmo espaço ou em espaços diferentes.

Esse prisma aventado e considerado por Souza (Ibid) encontra espaço no entendimento dos territórios articulados em rede, fato que torna imprescindível para a compreensão e análise dos fenômenos socio-espaço-territoriais hodiernos.

Ainda para Souza (lbid), os territórios são campos de forças, são antes teias de relações sociais projetadas no espaço, no qual não necessita de forte enraizamento material para que se tenha território, é definido por e a partir de relações de poder, engendradas por relações de influências, de autoridade, de força, de legitimidade e de subserviência.

\section{Considerações finais}

O que mostramos foi que os conceitos e categorias espaciais têm suas singularidades e suas concepções não devem ser utilizadas aleatoriamente, sem critérios de diferenciação, de modo genérico, sem fundamento teórico. Assim, entendemos que em determinados casos um determinado conceito e categoria deve se sobressair em relação a outro, obviamente que isso vai depender do objeto de nossas pesquisas, da abordagem que queiramos efetivar a determinado contexto da realidade sócio-espacial.

Nesse sentido, quando estivermos tratando das singularidades em termos de formas, atividades, significados e valores à compreensão da espacialidade e territorialidade humana, entendemos que a o conceito de lugar deve ser ativo, isto é, deve emergir, deve ser escolhido como conceito para essa determinada compreensão.

Por outro lado, quando estivermos analisando aspectos visuais, estéticos, de ordem cênica em uma perspectiva experiencial, simbólica, subjetiva de recepção visual e de (re)significação espacial, própria da relação humana com o espaço, o conceito de paisagem é a que melhor se encaixa.

Para uma análise territorial devemos perceber as relações de poder frente ao controle e à gestão do espaço, na medida em que isto seja salutar para a compreensão da sociedade em seu usufruto do espaço, nesse caso o conceito de território é o mais indicado.

Observamos, por fim, que o geógrafo é um pesquisador e cientista espacial fundamental na elucidação desses conceitos e categorias espaciais, posto que caso ocorra o uso desarticulado e sem critérios de tais conceitos, estaremos sob pena de uma intensa confusão de compreensão do construto que a sociedade em seus vários embates com o aporte natural e cultural vem desenvolvendo, e isso passa necessariamente pela relação em que a sociedade desenvolve com os espaços, lugares, paisagens e territórios, dentro de suas especificidades de compreensão e análise.

\section{Referências bibliográficas}

CORREAA, R. L. e ROSENDAHL, Z. (Orgs.). Paisagem, tempo e cultura. Rio de Janeiro: Editora da UERJ, 1998.

COSGROVE, D. A geografia está em toda parte: cultura e simbolismo nas paisagens humanas. In: FERREIRA, L. F. Acepções recentes do conceito de lugar e sua importância para o mundo contemporâneo. Território, Rio de Janeiro, n. 9, p.65-83, jul./dez. 2000.

Geografia Ensino \& Pesquisa, v. 16, n.2 p. 23 - 30, maio/ago. 2012

GOMES, P. C. C. Geografia e modernidade. Rio de Janeiro, Bertrand, 2000.

A condição urbana: ensaios de geopolítica da cidade. Rio de Janeiro: Bertrand, 2002.

Lopes, J. G. 
HOLZER, W. O lugar na geografia humanista. Território, Rio de Janeiro, n.7, p.7-78, jul./dez. 1999.

LOPES, J. G. A (re) construção do território e da dignidade camponesa no assentamento Cachoeira do Fogo-Independência/CE, Fortaleza: dissertação de mestrado apresentada ao Prodema - UFC, 2009.

RAFFESTIN, Claude. Por uma geografia do poder. São Paulo: Ática, 1993.

SANTOS, M. A natureza do espaço: técnica e tempo, razão e emoção. São Paulo: Hucitec, 1999.

SAQUET, Marcos Aurélio. O território: diferentes interpretações na literatura italiana. In: RIBAS, A. D.; SPOSITO, E. S.; SAQUET, M. A. Território e Desenvolvimento: diferentes abordagens. Francisco Beltrão: Unioeste, 2004.

SOJA, E. W. Geografias pós-modernas: a reafirmação do espaço na teoria social crítica. Rio de Janeiro: Jorge Zahar, 1993.

SOUZA, M. J. L. O território: sobre espaço e poder, autonomia e desenvolvimento. In: CASTRO, I. E.; GOMES, P. C. C.; CORREAA, R. L. (Orgs.). Geografia: conceitos e temas. Rio de Janeiro: Bertrand, 1995. p.77-116.

SPOSITO, E. S. SAQUET, M. A. Território e desenvolvimento: diferentes abordagens. Francisco Beltrão: Unioeste. 2004

TUAN, Y. Espaço e lugar: a perspectiva da experiência. São Paulo:

\section{Correspondência:}

Jecson Girão Lopes - Rua José Moreira 581 - Fortaleza-Ce. Cep: 60873195

E-mail: jecsang@yahoo.com.br

Recebido em 03 de janeiro de 2012.

Revisado pelo autor em 01 de fevereiro de 2012.

Aceito para publicação em 10 de fevereiro de 2012. 